2011s-77

\title{
Transboundary Movement of Waste: Second-hand Markets and Illegal Shipments
}

\author{
Sophie Bernard
}

\begin{tabular}{c}
\hline Série Scientifique \\
Scientific Series
\end{tabular}

Montréal

Décembre 2011

(C) 2011 Sophie Bernard. Tous droits réservés. All rights reserved. Reproduction partielle permise avec citation du document source, incluant la notice $($ ).

Short sections may be quoted without explicit permission, if full credit, including (C) notice, is given to the source.
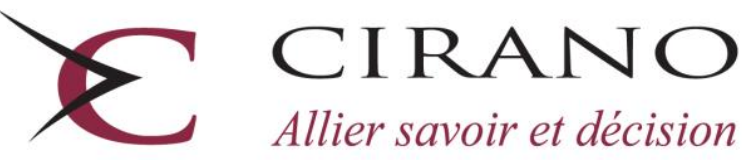

Allier savoir et décision

Centre interuniversitaire de recherche en analyse des organisations 


\section{CIRANO}

Le CIRANO est un organisme sans but lucratif constitué en vertu de la Loi des compagnies du Québec. Le financement de son infrastructure et de ses activités de recherche provient des cotisations de ses organisations-membres, d'une subvention d'infrastructure du Ministère du Développement économique et régional et de la Recherche, de même que des subventions et mandats obtenus par ses équipes de recherche.

CIRANO is a private non-profit organization incorporated under the Québec Companies Act. Its infrastructure and research activities are funded through fees paid by member organizations, an infrastructure grant from the Ministère du Développement économique et régional et de la Recherche, and grants and research mandates obtained by its research teams.

\section{Les partenaires du CIRANO}

\section{Partenaire majeur}

Ministère du Développement économique, de l'Innovation et de l'Exportation

\section{Partenaires corporatifs}

Autorité des marchés financiers

Banque de développement du Canada

Banque du Canada

Banque Laurentienne du Canada

Banque Nationale du Canada

Banque Royale du Canada

Banque Scotia

Bell Canada

BMO Groupe financier

Caisse de dépôt et placement du Québec

\section{CSST}

Fédération des caisses Desjardins du Québec

Financière Sun Life, Québec

Gaz Métro

Hydro-Québec

Industrie Canada

Investissements PSP

Ministère des Finances du Québec

Power Corporation du Canada

Rio Tinto Alcan

State Street Global Advisors

Transat A.T.

Ville de Montréal

\section{Partenaires universitaires}

École Polytechnique de Montréal

HEC Montréal

McGill University

Université Concordia

Université de Montréal

Université de Sherbrooke

Université du Québec

Université du Québec à Montréal

Université Laval

Le CIRANO collabore avec de nombreux centres et chaires de recherche universitaires dont on peut consulter la liste sur son site web.

Les cahiers de la série scientifique (CS) visent à rendre accessibles des résultats de recherche effectuée au CIRANO afin de susciter échanges et commentaires. Ces cahiers sont écrits dans le style des publications scientifiques. Les idées et les opinions émises sont sous l'unique responsabilité des auteurs et ne représentent pas nécessairement les positions du CIRANO ou de ses partenaires.

This paper presents research carried out at CIRANO and aims at encouraging discussion and comment. The observations and viewpoints expressed are the sole responsibility of the authors. They do not necessarily represent positions of CIRANO or its partners. 


\title{
Transboundary Movement of Waste: Second-hand Markets and Illegal Shipments*
}

\author{
Sophie Bernard ${ }^{\dagger}$
}

\section{Résumé / Abstract}

In a stylized model of international trade, firms in the North indirectly export second-hand products to a representative firm in the South to be reused as intermediate goods, with potential trade gains. The level of reusability of waste products is a crucial choice variable in the North. This is because, in the presence of imperfect international monitoring, non-reusable waste can be illegally mixed with reusable waste. I explore the driving forces for illegal waste movement, with a particular focus on local waste regulations such as the EU's Directive on Waste Electrical and Electronic Equipment.

Under mild conditions, it is shown that increasingly stringent regulations in the North induce Northern firms to reduce product reusability. Consequently, the flow of non-reusable waste to the South increases, magnifying the pollution haven effect.

Mots clés : waste, second-hand products, environmental regulations, trade, green design, illegal market.

Codes JEL: F18, L10, O13, Q53, Q56

\footnotetext{
${ }^{*}$ Research partly supported by the FQRSC (Fonds québécois de recherche sur la société et la culture) and Région Île-de-France.

${ }^{\dagger}$ Departement of Mathematics and Industrial Engineering, École Polytechnique Montréal, C.P. 6079, Succ.Centre-ville, Montréal (Qc), H3C 3A7, Canada. Tel.:+15143404711x5861, fax:+15143404173. Email address: sophie.bernard@polymtl.ca.
} 


\section{Introduction}

Using a North-South model, this paper analyzes the impact of extended producer responsibility (EPR) programs on the environment and illegal waste shipments when EPR programs may also affect firms' incentive for green design.

The scarcity of traditional landfill capacity combined with growing amounts of postconsumer waste has become a major concern for industrialized countries. Waste reuse has been proposed as a solution. Accordingly, governments have recently introduced new regulations, called extended producer responsibility (EPR) regulations, which make producers accountable for waste disposal costs and establish recycling and reuse objectives. The European Union's directives on Waste Electrical and Electronic Equipment (WEEE) and End of Life Vehicle (ELV), introduced in 2005 and 2006, are examples.

Waste moves naturally from developed to less developed countries. A driving force for these transboundary shipments is the difference in treatment and disposal costs between the North and South, explained by both the disparity in local waste regulations and the labor intensity of waste reuse industries. In particular, EPR programs implemented in rich countries confer a comparative advantage on firms in developing economies, where waste regulations are less stringent. The North-South movement of waste is also demand-driven. In developed countries, the demand for second-hand goods is often low due to technological obsolescence or regulations (e.g., technical inspections in many European countries that ensure that vehicles in poor condition must be taken off the road). The wealth gap between industrialized and industrializing economies explains the greater demand in developing countries for many types of e-waste, used vehicles, ${ }^{1}$ and recycled materials [Janischweski et al. 2003, Beukering and Bouman 2001].

Two important sets of regulations govern transboundary waste movement. Both the Basel

\footnotetext{
${ }^{1}$ Janischweski et al. (2003) showed that countries in East and West Africa import more second-hand vehicles than new ones. These cars are of a particularly poor quality, and are often more than 15 years old.
} 
Convention and the EU regulations restrict waste shipments and disposal. Non-OECD countries often have low-cost, albeit environmentally inadequate, facilities. For instance, exported e-waste often ends up incinerated in open fires, an unsafe practice for both the environment and human health [EEA 2009]. Under the above-cited international regulations, exporting hazardous waste from OECD to non-OECD countries is prohibited. ${ }^{2}$ The hazardous content of e-waste and end-of-life vehicles justifies trade restrictions in these markets.

In order to minimize the cost of complying with EPR programs, firms may undertake both legal and illegal ${ }^{3}$ waste shipments. In her investigation of this market, New York Times reporter Elisabeth Rosenthal (September 27, 2009) reported that, according to expert estimates, about $16 \%$ of exports are illegal. She also emphasized that the fewer restrictions on waste exported from the United States and Canada produce a larger flow of waste that is legally exported to developing countries. Other sources say that illegal shipments reported by non-OECD countries amount to 22,000 tonnes per year on average, or $0.2 \%$ of all notified waste [EEA 2009]. These illegal activities take different forms: transporting waste on the black market, mixing different types of waste, or declaring hazardous waste as non-hazardous. This study focuses on yet another illegal practice: classifying waste as second-hand goods.

When products are classified as second-hand goods, they are no longer governed by international waste regulations, and can be traded to developing countries. Yoshida and Terazono (2010) analyzed the reuse of second-hand TVs in the Philippines. Their survey of 113 Filipino consumers showed that around $40 \%$ of TVs exported from the EU were defective. They proposed that a systematic electrical testing would reduce by approximately half the shipment of second-hand EEE. These bads turned into goods constitute an economic incentive for misclassification. For instance, it costs about $£ 5$ to recycle a 'visibly undamaged' PC monitor in the UK, whereas traders are willing to pay up to $£ 3$ on the international

\footnotetext{
${ }^{2}$ Under the Basel Convention, the so-called Ban Amendment comes into force on a voluntary basis. Ratification by 17 additional parties is needed for the Amendment to enter into force.

${ }^{3}$ The US imposes fewer restrictions on waste exports than Europe because it did not ratify the Basel Convention. Consequently, US waste shipments are generally legal.
} 
market [Czarnomski and Webb 2006].

Authorities from developing countries can also turn a blind eye to these illegal markets. Reluctant to strengthen monitoring, they prefer to protect the imported waste business and the labor market it generates [Yardley, April 23, 2010].

Several used-good market characteristics testify to imperfect international monitoring. The first is that second-hand goods appear to be a one-size-fits-all category for recyclable, remanufacturable, and second-hand products. Owing to this institutional ambiguity, authorities and enforcement agencies can misclassify waste as used goods [Fischer et al. 2008]. Such misclassifications have been observed for e-waste and used vehicles ${ }^{4}$ [Czarnomski et al. 2006 and Janischweski et al. 2003], as well as used clothes, car tires, and other types of waste [Fischer et al. 2008].

Another outcome of imperfect monitoring is that many used products are traded alongside new products, which makes it hard to keep track. One way to assess the scale of these markets is to compare prices. For instance, the average price for all television sets exported from Europe is $339 €$, but the price drops to $28 €$ when they are exported to Nigeria, Ghana, or Egypt (where more than 1,000 used television sets arrive daily) [EEA 2009]. This lack of precision makes it difficult to conduct an accurate market analysis on either waste or used goods [EEA 2009].

The US and India, as well as other countries, led the discussions during the Doha Round. They wanted the World Trade Organization (WTO) to undertake initiatives to regulate the movement of used products. Today, the WTO has only a draft version of the proposed legislation, which recommends banning the import of used products. Consequently, developed countries can envisage a shrinking market for their used products. ${ }^{5}$ However, with the

\footnotetext{
${ }^{4}$ Czarnomski et al. (2006) observed that a significant amount of what is considered WEEE in OECD countries is illegally exported to West Africa as second-hand goods. In addition, Janischweski et al. (2003) noted that transactions where vehicles exported in 'top condition' turn out to be 'cars without an engine' are so common that they call it the Lemon Rule.

${ }^{5}$ Whereas some countries forbid the import of used goods, others apply prohibitive tariffs. Uganda qualifies used goods as 'sensitive,' and applies an extra 55\% tariff on top of the usual $25 \%$ external tariff.
} 
appropriate regulations, a liberalized trade in used goods would result in potential gains, as argued by Clerides (2008).

The present paper examines the effect of more stringent waste regulations, or higher disposal costs, in the presence of an international second-hand goods market. In a stylized North-South model, a representative firm in the South can purchase second-hand products from a firm in the North as intermediate goods. Due to imperfect monitoring, illegal shipments of non-reusable waste are mixed with the exported goods. The model explores the driving forces of illegal waste movement, with a focus on differences in local disposal costs. The impact of improved international monitoring is also considered. In this model, firms must adhere to an EPR program such as the WEEE directive.

In order to comply with the WEEE directive, producers can join one of the producer responsibility organizations (PROs). ${ }^{6}$ PROs are non-profit, government-recognized consortia that collect and manage end-of-life products. The management and waste disposal costs are charged to producers according to the contract between the PRO and the member producers. Products are divided into categories (e.g., small appliances weighing less than 25 grams, mobile phones, PC monitors greater than 32 inches in size), and the price for each end-of-life product is the average management cost for its category. If a goods category benefits from export revenues, for instance in a second-hand market, the net management cost is reduced, along with the price charged to the producers. Members are either owners or stockholders of the PROs. Decisions on the classification of waste as second-hand products are centralized at the PRO level.

One rationale behind EPR programs is that by internalizing the cost of waste disposal, firms will choose greener designs in order to improve reusability. Walls (2006) studied the

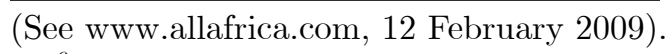

${ }^{6}$ For instance, in France, Eco-systèmes groups over 30 stockholders, including LG, Moulinex, Philips, and Samsung (see www.eco-systemes.com), while the European Recycling Platform was founded by Braun, Electrolux, HP, and Sony (see www.erp-recycling.org). The remaining two are Ecologic (see www.ecologicfrance.com) and Recylum (www.recylum.com). Recylum deals with used lamps only. 
impact of EPR on product design. She found that collective take-back programs involving consortia such as PROs may not provide enough incentive to spur greener design. Although they might require closer monitoring, individual programs where producers are responsible for their own end-of-life products would be more effective in this sense. Walls also reported the case of Braun, Electrolux, HP, and Sony, who founded their own PRO, whereby the four producers benefit from scale economies while avoiding problems related to collective actions.

The type of signed contract between producers and the PRO is a key determinant for green design. In France, prior to 2009, PROs did not differentiate between different levels of reusability across products within each waste category. This type of contract provided little incentive for green design, because any additional revenue resulting from individual efforts toward greener design was redistributed to all the producers. Since 2009, PROs must encourage EEE producers to invest in green design in order to improve product recyclability, lifetime, and reusability [Grenelle 1 law, article 41, 2009]. Now, contracts propose a price schedule according to product differentiation (green-designed versus non green-designed). However, in the EEE sector, product differentiation can be costly. A third type of contract has been discussed, and might emerge in the near future. In this contract, producers would be encouraged to collude through the PRO in order to determine a standard level of reusability. This 'legislated' collusion evokes the 1993 National Cooperative Research and Production Act in the US, which promotes innovation and R\&D.

The present paper discusses the impact of EPR programs on green design, and more precisely, on the level of reusability. In the model, incentives for green design stem from either a legislated collusion under the PRO or the small number of firms (as mentioned above by Walls in the case of Braun, Electrolux, HP, and Sony). The pollution haven hypothesis $(\mathrm{PHH})$ stipulates that larger differences in environmental regulations between two countries induce polluting industries to delocalize where the standards are weak. As predicted by this hypothesis, results show that in the absence of green-design incentives, a greater difference in environmental standards between the North and South causes a greater 
flow of waste toward the laxest country. When green-design incentives are introduced, the outcomes depend on the sign and amplitude of the incentives, which in turn depend on the initial difference in standards. In particular, if there is a small initial difference, then the tightening of the regulations in the North (i.e., the increased difference in standards between the two countries) stimulates green design, reduces illegal shipments, and reduces pollution in the South, thereby contradicting the PHH. However, a large difference in waste treatment costs between the South and North can induce firms in the North to reduce reusability in response to more stringent environmental regulations. This counterintuitive behaviour exacerbates the pollution haven effect. Increased international monitoring leads to similar results, depending on the firms' green-design response. The model underscores how more stringent environmental regulations or international monitoring that ignore the impact on green design can have adverse consequences on the environment and illegal shipments.

The literature on EPR programs has grown substantially in recent years. ${ }^{7}$ For instance, Runkel (2003) studied the influence of four instruments on product durability and welfare. Similarly to the current model, Runkel recognized the potential impact of EPR on green design. He also explored different competitive environments and showed that EPR programs applied under imperfect competition can lead to reduced welfare. Fleckinger and Glachant (2010) are concerned with the fact that these programs are designed precisely for producers to fulfill their obligations as they see fit. They examined a duopoly of producers and compared scenarios where producers managed their waste on their own or colluded through a PRO. They concluded that this type of collusion could lead to suboptimal outcomes, justifying government intervention. The EPR literature has largely neglected the international dimension. One objective of this paper was therefore to explore the impact of EPR on trade in waste and used products.

Few authors have studied the trade in waste and used products. From a theoretical perspective, Copeland (1991) studied international trade in waste disposal services. He found

\footnotetext{
${ }^{7}$ In addition to Walls (2006), see for instance OECD (2004) and Ino (2007).
} 
that in the presence of local illegal waste disposal, trade restrictions may improve welfare. Kinnaman and Yokoo (2011) proposed a North-South model of trade in waste reuse. They found that Pareto optimality is reached when the difference in e-waste taxation rates between the two countries is equal to the difference in their respective external marginal cost of ewaste. Empirically, Bond (1983) developed a model based on differences in factor prices and technologies to explain trade in used equipment between firms. Frazer (2008) explained the decline in apparel production in Africa due to used-clothing donations, ${ }^{8}$ and Clerides (2008) described the gains from trade in used vehicles. Baggs (2009) and Kellenberg (2010) both attempted to explain the PHH by the trade pattern of waste. In particular, Kellenberg found that waste moves toward countries with less stringent regulations. The present paper adds two dimensions to this literature: illegal shipments due to imperfect monitoring, and incentives for green design.

\section{The Model}

The problem is set in a basic model of international trade where a representative firm in a developing country (the South) imports inputs (used products) from a representative firm in a developed country (the North).

New final goods are produced in quantity $x_{N}$ by a representative firm in the North and they are consumed at home. The firm faces a decreasing inverse demand for its new products:

$$
p_{N}=\beta-x_{N},
$$

where $\beta$ stands for the North's market size. At the end of products lifetime, the firm is subjected to an EPR program managed through a PRO. For simplicity, the PRO's activities are merged with the firm's objective function.

\footnotetext{
${ }^{8}$ Similar to food aid, used-clothing imports harm local producers. Used-good imports as an obstacle to economic development is also discussed in detail by Janischweski et al. (2003).
} 
A proportion of the end-of-life products are classified as exportable, and can be traded to the South as inputs to production. Under the EPR program, non-exported products must be disposed of in an eco-friendly manner, at a constant unit cost of disposal $d_{N}$.

The firm in the South is representative of a market in perfect competition. On the international second-hand market, the firm buys a basket of used products that were previously classified as exportable. The firm can either apply some transformation processes like cleaning, remanufacturing, or repairing, or it can act as an intermediary for shipping, handling, or reselling. One reusable good is required for the production of one output. On the local market, $x_{S}$ final goods are sold at price $p_{S}$.

The South can also adopt an EPR program, whereby the firm is responsible for the unit waste disposal cost $d_{S}$.

\subsection{International regulation and monitoring}

Let $q$ denote the proportion of goods $x_{N}$ that are reusable at the end of life. In Figure 1, Case 1 shows how, in the absence of international regulations (i.e., no monitoring), reusable and non-reusable products are classified as exportable. Consequently, exports are a subset of all end-of-life products, $w \leq x_{N}$. The purity of the exported basket $\rho$ is the ratio of reusable products in the basket of exported goods. In the absence of monitoring, purity is simply the level of reusability $q$.

When an international regulation for waste is introduced, the share of non-reusable products should not be exported to the South. However, imperfect monitoring means that a fraction $\sigma \in(0,1)$ of these non-reusable goods is misclassified. The actual fraction of used goods classified as exportable is $q+(1-q) \sigma$. Consequently, basket purity becomes:

$$
\rho \equiv q /(q+(1-q) \sigma)
$$

For a given level of reusability $q$, the set of exportable products is therefore smaller and purer 
Case 1: Without international regulation $\sigma=1$

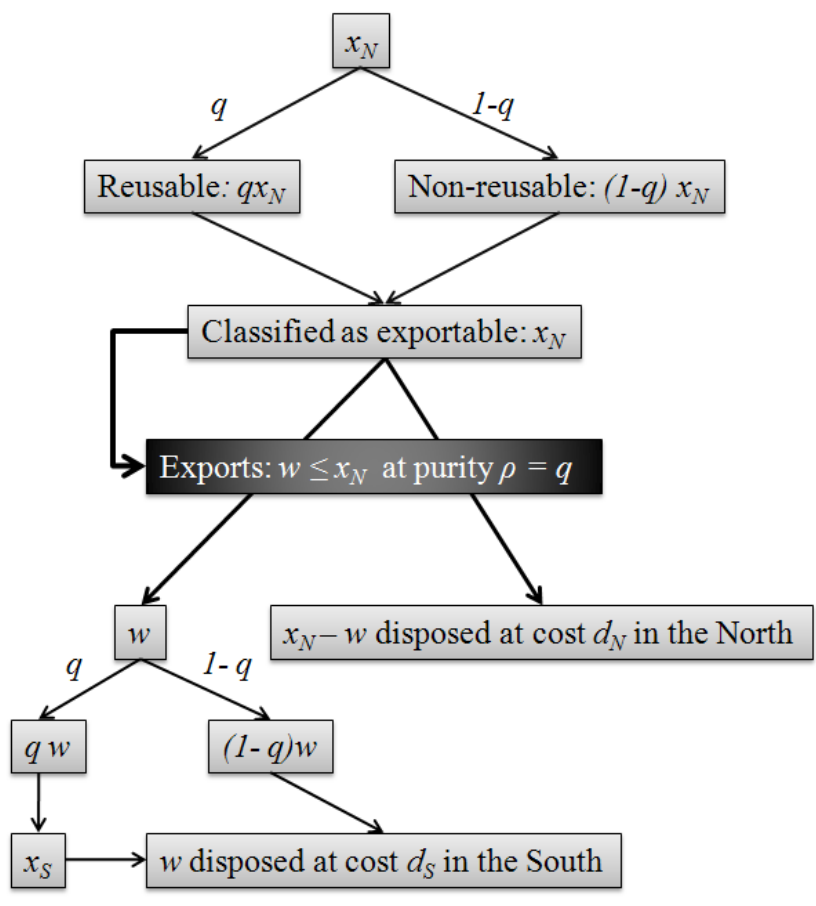

Case 2: With international regulation $0 \leq \sigma \leq 1$

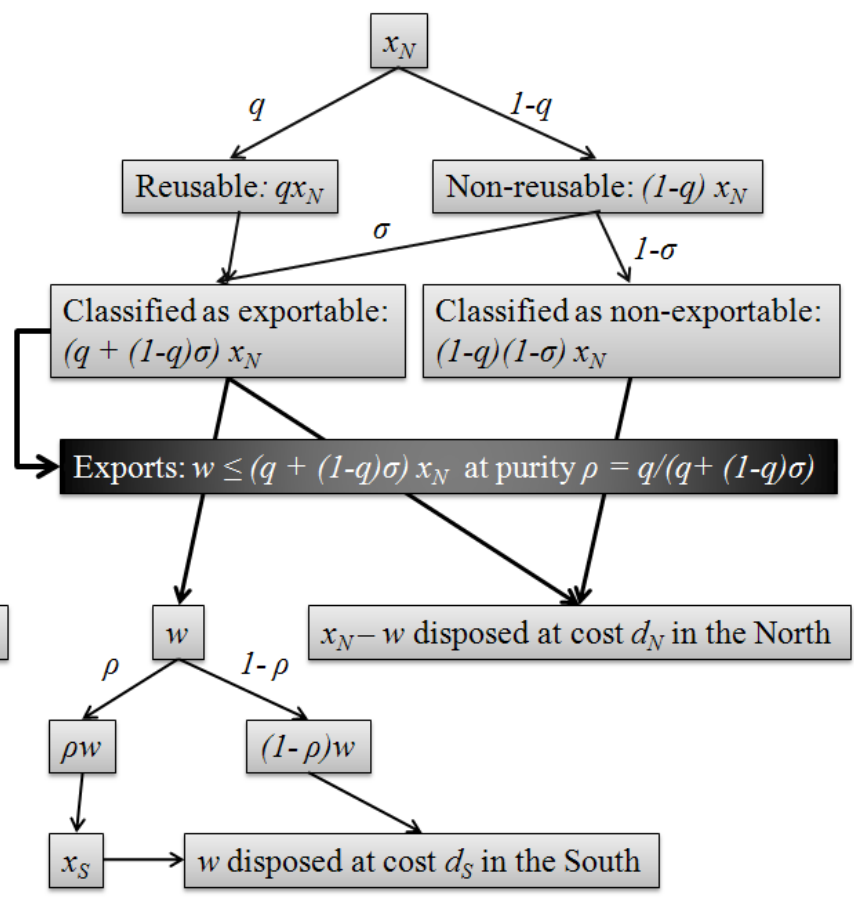

Figure 1: Waste movement

as monitoring increases. This is shown in Figure 1 Case 2.

In order to examine the $\mathrm{PHH}$, it is assumed that the South's environmental regulations for waste disposal are laxer than the North's: $d_{S} \leq d_{N}$. Hereafter, $D \equiv d_{N}-d_{S}$.

It is also assumed that the products have a natural rate of reusability. This means that in the absence of initial investment in green design, products can be reusable at a rate $q_{0} \in[0,1]$. Through green design, the firm in the North can increase its fraction of reusable products $q$ at a unit production $\operatorname{cost} c_{N}(q)$ such that $c_{N}^{\prime}(q)=0$ for $q \leq q_{0}$, while $c_{N}^{\prime}(q) \geq 0$ and $c_{N}^{\prime \prime}(q) \geq 0$ for $q>q_{0}$.

In the South, the production costs reflect the sorting and transformation processes, which decrease with $\rho$. Once sorted as reusable, goods require different degrees of intervention- 
from simple cleaning to a change in parts - and the marginal production cost increases with $x_{S}$. These transformation costs take the form: $c_{S}\left(x_{s} ; \rho\right)=x_{s}^{2} / 2 \rho$.

\subsection{Market structure}

The market structure is described by the following two-stage game. Local disposal costs, $d_{S}$ and $d_{N}$, and the state of (or lack of) monitoring $\sigma$ are given.

In the first stage, the firm in the North selects the level of reusability $q$, the initial production $x_{N}$ and the level of exports $w$. Because the firm in the North is representative of a market in perfect competition, the price $p_{N}$ is taken as given when production $x_{N}$ is chosen. For the level of exports, however, the decision is centralized through the PRO such that the firm acts like a monopolist. Two scenarios are explored for the choice of $q$ : non-cooperation and collusion. In non-cooperation, the level of purity $\rho$ is taken as given.

The representative firm in the South is a price taker on the international market, whereas the firm in the North is the leader. In the second stage, the level of imports as well as the quantity of outputs, $w$ and $x_{S}$, are determined in the South.

\section{The equilibrium}

The profit functions for the firm in the North and South are respectively

$$
\begin{aligned}
\pi_{N}= & p_{N} x_{N}-c_{N}(q) x_{N}+p_{w} w-\left(x_{N}-w\right) d_{N} \\
& \text { where } w \leq(q+(1-q) \sigma) x_{N} \\
\pi_{S}= & p_{S} x_{S}-c_{S}\left(x_{S} ; \rho\right)-\left(p_{w}+d_{S}\right) w \\
& \text { where } c_{S}\left(x_{s} ; \rho\right)=x_{s}^{2} / 2 \rho \\
& \text { and } x_{S} \leq \rho w
\end{aligned}
$$


Equation 1 means that the firm in the North cannot export more than the proportion of used goods classified as exportable. It is assumed that the international market is sufficiently small so that this equation is not binding in equilibrium. The scenario of a corner solution, where the South imports all goods classified as exportable, is not considered here. ${ }^{9}$ Equation (2) states that the firm's output in the South is limited by the amount of reusable inputs $\rho w$.

Using backward induction, the final stage is solved first. In equilibrium, all reusable inputs are transformed into outputs, and the constraint $(2)$ is binding: $x_{S}=\rho w$. The representative firm's problem is:

$$
\max _{w} \pi_{S}=p_{S} \rho w-(\rho w)^{2} / 2 \rho-\left(p_{w}+d_{S}\right) w
$$

The first-order condition leads to the following reaction demand function for imported goods:

$$
p_{w}=p_{S} \rho-w \rho-d_{S}
$$

The first stage in the game is the Northern firm's problem. Using equation (3), the problem becomes:

$$
\max _{w, x_{N}, q} \pi_{N}=p_{N} x_{N}-c_{N}(q) x_{N}+\left(p_{S} \rho-w \rho-d_{S}\right) w-\left(x_{N}-w\right) d_{N}
$$

With the difference in disposal cost $D \equiv d_{N}-d_{S}$, this can be written as

$$
\max _{w, x_{N}, q} \pi_{N}=p_{N} x_{N}-c_{N}(q) x_{N}-x_{N} d_{N}+\underbrace{\left(p_{S} \rho-w \rho\right) w+D w}_{\pi_{w}: \text { net benefit of export }} .
$$

\footnotetext{
${ }^{9}$ This implies that $\beta$ is sufficiently large. Formally, $\beta>\left(p_{s} \bar{q}+D\right) \frac{2+2 \rho(q+(1-q) \sigma)^{2}}{q}+c_{N}(q)+d_{N}$.
} 
Using $p_{N}=\beta-x_{N}$, the first-order conditions lead to:

$$
\begin{aligned}
& w^{*}=\frac{p_{S} \rho^{*}+D}{2 \rho^{*}} \\
& x_{N}^{*}=\beta-c_{N}\left(q^{*}\right)-d_{N}
\end{aligned}
$$

The export price is:

$$
p_{w}^{*}=\frac{p_{S} \rho^{*}-d_{N}-d_{S}}{2}
$$

For analysis purposes, illegal shipments $I$, which is the non-reusable share of exports, takes the form:

$$
I \equiv\left(1-\rho^{*}\right) w^{*}
$$

Note that in the absence of green design, equation (5) shows the direct channel for the PHH. The difference in regulations between the North and South $D$ drives the export of reusable and non-reusable waste. This partially echoes Kinnaman and Yokoo's (2011) finding that Pareto optimality depends on the difference in e-waste taxes between countries, and not tax levels. 


\subsection{Non-cooperation and collusion}

\subsubsection{Green design}

The choice of reusability is set either in non-cooperation or collusion. Knowing that the level of purity $\rho$ is taken as given in non-cooperation, the optimality conditions are

$$
\begin{aligned}
\frac{d \pi_{N}}{d q} & =-c_{N}^{\prime}\left(q^{n c}\right) x_{N}^{*} \leq 0 \Leftrightarrow q^{n c}=q_{0} \\
\frac{d \pi_{N}}{d q} & =-c_{N}^{\prime}\left(q^{c}\right) x_{N}^{*}+\frac{\partial \rho^{*}}{\partial q}\left(\frac{\left(\alpha \rho^{*}\right)^{2}-D^{2}}{4 \rho^{*}}\right)=0
\end{aligned}
$$

where the superscripts $n c$ and $c$ denote the equilibrium in non-cooperation or collusion. Hence $q^{*}=\left\{q^{n c}, q^{c}\right\}$. It is assumed that the second-order condition for a maximum is respected. Note that equation (9) again highlights the role of the difference in disposal costs. Equations (8) and (9) say that the choice of reusability in the case of non-cooperation $q^{n c}$ is restricted to the natural rate of reusability $q_{0}$, whereas collusion leads to an investment in greener design $q^{c}$. This is stated in the following proposition.

Proposition 1 Collusion, compared to non-cooperation, leads to higher reusability:

$$
q^{n c}=q_{0} \leq q^{c} .
$$

\subsubsection{Illegal shipments and pollution}

In equilibrium, the environmental damage functions take the following forms:

$$
\begin{aligned}
Q_{N} & =Q\left(d_{N}\right)\left(x_{N}^{*}-w^{*}\right) \\
Q_{S} & =Q\left(d_{S}\right) w^{*} \\
Q_{W o r l d} & =Q\left(d_{N}\right) x_{N}^{*}+\left(Q\left(d_{S}\right)-Q\left(d_{N}\right)\right) w^{*}
\end{aligned}
$$


$Q_{N}$ and $Q_{S}$ stand for local pollution in the North and South and $Q_{W o r l d}$ stands for global pollution. Stricter waste regulations reduce pollution, hence $Q^{\prime}(\cdot) \leq 0$.

Proposition 2 Collusion, compared to non-cooperation, leads directly to higher purity, lower production in the North, and lower exports, i.e., $\rho^{n c} \leq \rho^{c}, x_{N}^{n c} \geq x_{N}^{c}$ and $w^{n c} \geq w^{c}$. The presence of lower exports at higher purity unambiguously leads to a reduction in illegal shipments:

$$
I^{n c} \geq I^{c}
$$

Collusion also results in reduced global pollution, and more particularly, reduced pollution in the South:

$$
Q_{S}^{n c} \geq Q_{S}^{c} \text { and } Q_{W o r l d}^{n c} \geq Q_{W o r l d}^{c}
$$

The impact on the level of pollution in the North is ambiguous.

The results in proposition 2 suggest that although the impact on environmental quality in the North is ambiguous, global pollution is invariably reduced, justifying collusion as an environmental policy. Note that by internalizing the externality, collusion produces greater profits, which means that industry in the North would collaborate with any environmental policy that promotes collusion. At the same time, the South benefits from fewer illegal shipments.

\section{Disposal costs and international monitoring}

The following set of results presents what occurs when there is a change in disposal cost or international monitoring. First, the impact of a change in policy on green design is presented. According to equations (8) and (9), i.e. the optimality conditions for the level of reusability, it is straightforward to see that green design varies in the collusion case but remains unchanged in the non-cooperation case. Hence, this section compares the two cases by highlighting the 
importance of incentives for green design. The impacts on illegal shipments and pollution are discussed.

\subsection{Disposal costs and the Pollution Haven Hypothesis}

\subsubsection{Green design}

One of the rationales for EPR is that by internalizing the cost of waste disposal, firms choose a higher level of reusability. The following presents what happens when the North applies stricter waste management regulations, and therefore higher disposal cost:

We have:

$$
\begin{aligned}
\operatorname{sign} \frac{d q^{c}}{d d_{N}} & =\operatorname{sign} \frac{\partial^{2} \pi_{N}}{\partial q \partial d_{N}} \text { where } \\
\frac{\partial^{2} \pi_{N}}{\partial q \partial d_{N}} & =c_{N}^{\prime}\left(q^{c}\right)+\frac{\partial \rho^{c}}{\partial q}\left(\frac{-2 D}{4 \rho^{c}}\right)
\end{aligned}
$$

Proposition 3 For all $q^{c}$, there exists a unique $\phi>0$ such that

$$
\frac{d q^{c}}{d d_{N}} \gtreqless 0 \Longleftrightarrow D \lesseqgtr \phi .
$$

In particular, for $D=0, d q^{c} / d d_{N}>0$. Note that $\phi$ depends on the initial value of $q^{c}$, determined by the equilibrium prior to the change in policy.

Proof: We know that $c_{N}^{\prime}(q)$ and $\partial \rho / \partial q$ are positive. Therefore, equation (11) strictly decreases when $D$ increases. Since $d q^{c} / d d_{N}>0$ when $D=0$, then $d q^{c} / d d_{N}=0$ when $D=\phi>0$.

When the South regulates as much as the North, i.e. $D=0$, the level of reusability $q$ increases unambiguously with the strength of local waste regulations $d_{N}$. However, when the difference between disposal costs is sufficiently large, more stringent waste regulations induce firms to reduce green design. 
To better understand the intuition behind Proposition 3, let consider the maximization problem for the choice of exports (from equation (4)):

$$
\max _{w} \pi_{w}=\left(p_{S} \rho-w \rho\right) w+D w=p(w) w-M C w
$$

This is a standard maximization problem for a monopolist, with the difference that the marginal cost $M C$, which includes the savings in disposal cost in the North, is negative (i.e., $M C=-D)$. The term $p(w)$ is an adjusted inverse demand function. This is illustrated in Figure 2, which presents four scenarios: combinations of low and high difference in disposal $\operatorname{costs}\left(D_{L}\right.$ and $\left.D_{H}\right)$ and low and high purity $\left(\rho_{L}\right.$, dashed lines; and $\rho_{H}$, solid lines). The demand curve is $p(w)=p_{S} \rho-w \rho$ and the marginal revenue curve $(M R)$ is $p^{\prime}(w) w+p(w)=$ $p_{S} \rho-2 w \rho$. For the four scenarios, the equilibrium is set at the intersection between the marginal cost and the marginal revenue, i.e., $M R=-D$ (points $\mathrm{C}$ to $\mathrm{F}$ ). Note that a reduction in purity (e.g., a change from $\rho_{H}$ to $\rho_{L}$ ) leads to greater demand elasticity and pivots the marginal revenue and demand curves to the left around points A and B. Therefore, below the horizontal axis, the demand shifts up.

It can be seen that, in the case of a standard positive marginal cost, a reduction in purity invariably leads to a drop in both prices and quantities, unambiguously resulting in lower benefit of export. However, when the marginal cost is negative, the drop in price is compensated by greater demand. Tightening regulations in the North makes the marginal cost more negative and exacerbates this effect. Comparative static,

$$
\frac{d \pi_{w}}{d \rho}=\frac{p_{S}^{2}}{4}-\frac{D^{2}}{4 \rho^{2}} \text { and } \frac{d^{2} \pi_{w}}{d \rho d D}=\frac{-D}{2 \rho^{2}}
$$

says that the marginal benefit of reducing purity $\rho$ increases with the difference in disposal $\operatorname{cost} D$ and becomes positive when $D$ is sufficiently large. Referring to equation (9), the choice of reusability, or indirectly the choice of purity, is set where the marginal benefit of 


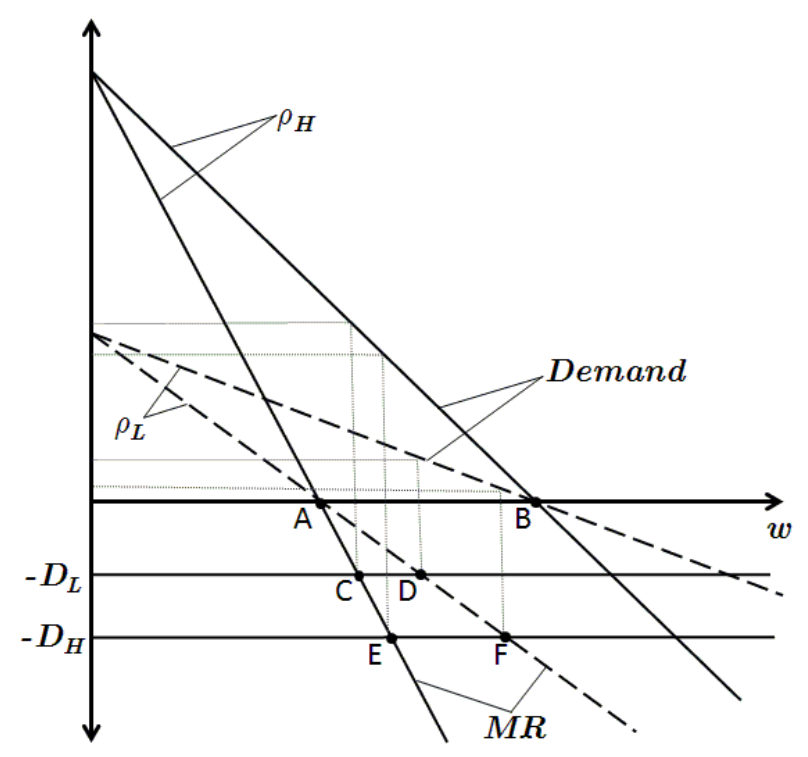

Figure 2: Effect of a change in purity on the net benefit of export

export is equal to the marginal cost of producing more reusable products. As $D$ increases, reducing reusability becomes more attractive.

In light of Proposition 3, the positive impact of EPR programs on green design holds when there is little difference between Northern and Southern local regulations. With increasing disposal cost in the North, colluding firms are more likely to consider the greater demand associated with lower purity instead of improving the level of reusability.

Proposition 4 In equilibrium, increased disposal cost in the South invariably increases the level of reusability.

$$
\operatorname{sign} \frac{d q^{c}}{d d_{S}}=\operatorname{sign} \frac{\partial^{2} \pi_{N}}{\partial q \partial d_{S}} \text { where } \frac{\partial^{2} \pi_{N}}{\partial q \partial d_{S}}=\frac{\partial \rho^{c}}{\partial q}\left(\frac{2 D}{4 \rho^{c}}\right) \geq 0
$$




\subsubsection{Illegal shipments and pollution}

The impact of a change in disposal cost in the North $d_{N}$ on illegal shipments and pollution depends on the incentive for firms in the North to adjust the level of product reusability. More particularly, it depends on the sign and the amplitude of this incentive. Using equations (5) to (10), and Proposition 3, we have:

Proposition 5 The following table summarizes the impact of tighter regulations in the North on the level of illegal shipments, pollution in the North and South, and global pollution. Case dn1: in the absence of green design (as in the non-cooperation case, $q^{*}$ is fixed), the change in disposal cost directly implies an increase in exports and a reduction in initial production.

Case dn2: green design greatly improves purity such that exports decrease despite the higher disposal cost. Higher production and disposal costs reduce initial production. This occurs only if $D<\phi$. Case dn3: the magnitude of the change in green design is small and the impact on exports and initial production is similar to Case dn1. Case dn4: a reduction in green design is sufficiently high for initial production to increase, despite the higher disposal cost. Lower purity and higher disposal cost increase exports. This occurs only if $D>\phi$. The sign $\gtrless 0$ denotes ambiguity.

\begin{tabular}{|l||c|c|c|c|}
\hline Case & $d n 1$ & $d n \mathcal{2}$ & $d n 3$ & $d n 4$ \\
\hline & $q^{*}$ fixed & $d q^{*} / d d_{N}>0$ & $d q^{*} / d d_{N} \gtrless 0$ & $d q^{*} / d d_{N}<0$ \\
& $d w^{*} / d d_{N}>0$ & $d w^{*} / d d_{N}<0$ & $d w^{*} / d d_{N}>0$ & $d w^{*} / d d_{N}>0$ \\
& $d x_{N}^{*} / d d_{N}<0$ & $d x_{N}^{*} / d d_{N}<0$ & $d x_{N}^{*} / d d_{N}<0$ & $d x_{N}^{*} / d d_{N}>0$ \\
\hline \hline$d I / d d_{N}$ & $>0$ & $<0$ & $\gtrless 0$ & $>0$ \\
\hline \hline$d Q_{N} / d d_{N}$ & $<0$ & $\gtrless 0$ & $<0$ & $\gtrless 0$ \\
\hline$d Q_{S} / d d_{N}$ & $>0$ & $<0$ & $>0$ & $>0$ \\
\hline$d Q_{\text {World }} / d d_{N}$ & $\gtrless 0$ & $<0$ & $\gtrless 0$ & $\gtrless 0$ \\
\hline
\end{tabular}


Case $\mathrm{dn} 1$ is in line with the $\mathrm{PHH}$, because a greater difference in environmental regulations between developed and less-developed countries results in a pollution (waste) flow toward poor countries. This result changes when there are incentives for adjusting green design, as in cases dn2 to dn4.

When the EPR is similar between the two countries, i.e., when $D<\phi$, the firm in the North, which internalizes the South's disposal cost, does not benefit from a large difference between local and foreign disposal costs. Therefore, the firm will increase the level of product reusability $q$, propose baskets with higher purity $\rho$, and benefit from higher prices on the export market. In Case dn2, illegal shipments, pollution in the South, and global pollution are reduced. Due to incentives for green design, a greater difference in environmental regulations between the North and South reduces the pollution flow toward the laxest country. This result contradicts the PHH.

When the EPR differs greatly between the two countries, i.e., when $D>\phi$, the firm in the North benefits from a large difference between its local disposal cost and the internalized South's cost. The firm's strategy will therefore be to export non-reusable goods, which are disposed of more cheaply in the South. The firm in the North will reduce product reusability $q$ and reduce the purity of exported baskets $\rho$. This strategy lowers the price of exports $p_{w}$ and increases the demand for used goods. With higher exports and lower purity, illegal shipments $I$ unambiguously increase. If purity were to remain high, the demand in the South would rapidly become saturated and the exports would remain too low relative to the increasing disposal cost in the North and the possibility of dumping non-reusable waste in the South. The change in green design magnifies the pollution haven effect.

Results in Proposition 5 show that only Case $\operatorname{dn} 2$ ensures a reduction in global pollution, which occurs only if tighter regulations stimulate green designs (i.e., $D<\phi$ ). This is also the only case that can lead to a simultaneous reduction in pollution in the North and South. Other scenarios, where pollution in the North unambiguously decreases, leave the impact on global pollution uncertain. Therefore, a change in disposal cost in the North that is 
driven by local environmentalists may not serve the interests of global environmentalists, and vice-versa.

As $D$ and $d q^{*} / d d_{N}$ change, the impacts on production, purity, and terms of trade vary. A well-designed regulation for waste management should therefore include firms' responses in terms of product design. Ignoring changes in product design may lead to adverse environmental impacts.

Using equations (5) to (10), and Proposition 4, we have:

Proposition 6 The following table summarizes the impact of tighter regulations in the South on the level of illegal shipments, pollution in the North and South, and global pollution. Case ds1: in the absence of green design (as in the non-cooperation case, $q^{*}$ is fixed), change in disposal cost directly reduces exports and leaves the initial production unchanged. Case ds2: an increase in disposal cost in the South invariably stimulates green design. Higher purity and disposal cost in the South reduce exports. Higher production cost reduces initial production.

\begin{tabular}{|l||c|c|}
\hline & $d s 1$ & $d s \mathcal{L}$ \\
\hline & $q^{*}$ fixed & $d q^{*} / d d_{S}>0$ \\
& $d w^{*} / d d_{S}<0$ & $d w^{*} / d d_{S}<0$ \\
& $d x_{N}^{*} / d d_{S}=0$ & $d x_{N}^{*} / d d_{S}<0$ \\
\hline \hline$d I / d d_{S}$ & $<0$ & $<0$ \\
\hline \hline$d Q_{N} / d d_{S}$ & $>0$ & $\gtrless 0$ \\
\hline$d Q_{S} / d d_{S}$ & $<0$ & $<0$ \\
\hline$d Q_{W \text { orld }} / d d_{S}$ & $<0$ & $<0$ \\
\hline
\end{tabular}

Tightening the environmental regulations in the South reduces illegal shipments as well as local and global pollution. If firms in the North adopt greener design, they may help prevent rising pollution in the North. 


\subsection{International monitoring}

\subsubsection{Green design and purity}

This section presents the impact of stronger international monitoring on the level of reusability. We have:

$$
\begin{aligned}
& \operatorname{sign} \frac{d q^{c}}{d \sigma}=\operatorname{sign} \frac{\partial^{2} \pi_{N}}{\partial q \partial \sigma} \text { where } \\
& \frac{\partial^{2} \pi_{N}}{\partial q \partial \sigma}=\frac{\partial^{2} \rho^{c}}{\partial q \partial \sigma}\left(\frac{\left(p_{S} \rho^{c}\right)^{2}-D^{2}}{4 \rho^{c}}\right)+\frac{\partial \rho^{c}}{\partial q} \frac{\partial \rho^{c}}{\partial \sigma}\left(\frac{\left(p_{S} \rho^{c}\right)^{2}+D^{2}}{4 \rho^{c}}\right) .
\end{aligned}
$$

The first term is the variation in the marginal revenue of exports due to a variation in the marginal effect of the level of reusability $q$. Considering the optimality condition for the choice of $q$ (equation 9 ), we know that $\left(p_{S} \rho^{c}\right)^{2}-D^{2}$ is positive in equilibrium. The second term in equation (12) is always negative. It represents the variation in the marginal revenue of exports due to a variation in the terms of trade.

Proposition 7 There exists $\psi>0.5$ such that

$$
\frac{d q^{c}}{d \sigma} \gtreqless 0 \Longrightarrow \rho^{c} \gtreqless \psi
$$

The effect of stronger international monitoring (a reduction in $\sigma$ ) on reusability $q^{c}$ depends on the initial value of purity $\rho^{c}$ prior to the change in policy.

Proof: Rearranging equation (12), we see that $\frac{d q^{c}}{d \sigma} \gtreqless 0 \Leftrightarrow \frac{\partial^{2} \rho^{c}}{\partial q \partial \sigma}\left(-\frac{\partial \rho^{c}}{\partial q} \frac{\partial \rho^{c}}{\partial \sigma}\right)^{-1} \gtreqless \frac{\left(p_{S} \rho^{c}\right)^{2}+D^{2}}{\left(p_{S} \rho^{c}\right)^{2}-D^{2}}$. The right-hand side is positive and decreasing in $\rho$. For the specific form of $\rho$, the left-hand side (let $\left.L H S=\frac{\partial^{2} \rho^{c}}{\partial q \partial \sigma}\left(-\frac{\partial \rho^{c}}{\partial q} \frac{\partial \rho^{c}}{\partial \sigma}\right)^{-1}\right)$ is constant for any given $\rho(q, \sigma)$ obtained with any combination of $q \in(0,1)$ and $\sigma \in(0,1)$, and it respects the following properties:

$$
\begin{aligned}
& \frac{\partial^{2} \rho^{c}}{\partial q \partial \sigma} \gtreqless 0 \Leftrightarrow L H S \gtreqless 0 \Leftrightarrow \rho \gtreqless 0.5 ; \text { and } \\
& \lim _{\rho \rightarrow 0} L H S=-\infty \text { and } \lim _{\rho \rightarrow 1} L H S=+\infty .
\end{aligned}
$$


Therefore, $\psi$ exists and occurs at $\psi>0.5$.

When purity is high, equation (14) becomes positive, which means that stronger international monitoring reduces the impact of green design on purity. When purity is sufficiently high, firms in the North are incited to reduce the level of reusability.

Most variables of interest in this model depend on purity $\rho$. A change in international monitoring affects purity directly as well as indirectly, through changes in green design. When an increase in international monitoring leads to a reduction in reusability, the two effects work in opposite directions.

Proposition 8 The total effect of stronger international monitoring (a reduction in $\sigma$ ) on purity $\rho$ is positive if and only if

$$
\frac{d \rho^{c}}{d \sigma}=\frac{\partial \rho^{c}}{\partial q} \frac{d q^{c}}{d \sigma}+\frac{\partial \rho^{c}}{\partial \sigma} \leq 0 \Longleftrightarrow \frac{d q^{c}}{d \sigma} \leq \frac{q^{c}\left(1-q^{c}\right)}{\sigma} .
$$

From propositions 7 and 8, if purity is initially small, then it increases with stronger international monitoring, i.e., $\rho^{c}<\psi \Leftrightarrow d q^{c} / d \sigma<0<q^{c}\left(1-q^{c}\right) / \sigma$. If international monitoring continues to strengthen, purity rises and becomes high when $\rho^{c}>\psi$.

In some circumstances, stronger international monitoring will have the opposite effect to what was intended. From Proposition 7, we know that this scenario occurs only when purity is initially high, i.e. $d q^{c} / d \sigma>q^{c}\left(1-q^{c}\right) / \sigma>0 \Longrightarrow \rho^{c}>\psi$. All else equal, stronger international monitoring directly increases purity. A firm that wishes to maintain a lower level of purity will therefore reduce its level of reusability. When purity is already high, the benefit of reducing purity through $q$ can be greater than the benefit, through the terms of trade, of maintaining high purity.

\subsubsection{Illegal shipments and pollution}

Using equations (5) to (10), and propositions 7 and 8, we have: 
Proposition 9 The following table summarizes the impact of stronger international monitoring (a reduction in $\sigma$ ) on illegal shipment, pollution in the North and South, and global pollution. Case $\sigma$ 1: in the absence of green design (as in the non-cooperation case, $q^{*}$ is fixed), stronger international monitoring directly improves purity, which lowers exports. Initial production is not affected. Case $\sigma 2$ : stronger international monitoring induces firms to choose a higher level of reusability. This directly and indirectly improves purity and lowers exports. Higher production cost reduces initial production. This occurs only if $\rho<\psi$. Case б3: stronger international monitoring induces firms to reduce reusability, whereas purity still increases. Higher purity reduces exports and lower production cost increases initial production. This occurs only if $\rho>\psi$. Case $\sigma 4$ : stronger international monitoring greatly reduces the incentive for reusability such that it lowers purity. Lower purity shifts the demand upward, and exports increase. Lower production cost stimulates initial production. This occurs only if $\rho>\psi$.

\begin{tabular}{|l||c|c|c|c|}
\hline Case & $\sigma 1$ & $\sigma \mathscr{2}$ & $\sigma 3$ & $\sigma 4$ \\
\hline & $q^{*}$ fixed & $d q^{*} / d \sigma<0$ & $d q^{*} / d \sigma>0$ & $d q^{*} / d \sigma>0$ \\
& $d \rho^{*} / d \sigma<0$ & $d \rho^{*} / d \sigma<0$ & $d \rho^{*} / d \sigma<0$ & $d \rho^{*} / d \sigma>0$ \\
& $d w^{*} / d \sigma>0$ & $d w^{*} / d \sigma>0$ & $d w^{*} / d \sigma>0$ & $d w^{*} / d \sigma<0$ \\
& $d x_{N}^{*} / d \sigma=0$ & $d x_{N}^{*} / d \sigma>0$ & $d x_{N}^{*} / d \sigma<0$ & $d x_{N}^{*} / d \sigma<0$ \\
\hline \hline$d I / d \sigma$ & $>0$ & $>0$ & $>0$ & $<0$ \\
\hline \hline$d Q_{N} / d \sigma$ & $<0$ & $\gtrless 0$ & $<0$ & $\gtrless 0$ \\
\hline$d Q_{S} / d \sigma$ & $>0$ & $>0$ & $>0$ & $<0$ \\
\hline$d Q_{W \text { orld }} / d \sigma$ & $>0$ & $>0$ & $\gtrless 0$ & $<0$ \\
\hline
\end{tabular}

Proposition 9 says that stronger international monitoring generally reduces illegal shipments, and accordingly, the level of pollution in the South. However, under some conditions, stronger monitoring when purity is high induces firms to downgrade green design, which 
diminishes purity (case $\sigma 4$ ). This intensifies illegal shipment, pollution in the South, and global pollution.

Only cases where purity is low, i.e., where $\rho<\psi$, or where there is no incentive for green design, ensure decreased global pollution as the result of stricter monitoring. The one who would like to strengthen monitoring in a purer economy, i.e., when $\rho>\psi$, should be aware of the adverse effects on the level of reusability.

\section{Conclusion}

This paper considered a North-South model whereby used durable goods in the North are imported by a firm in the South as inputs to production. Imperfect international monitoring allows illegal waste to be mixed with reusable products.

The Pollution Haven Hypothesis (PHH) was examined, with special attention given to the impact of incentives for green design. In the presence of large differences in local waste regulations between the two countries, it appears that extended producer responsibility (EPR) programs, which make producers accountable for the cost of waste disposal, incite firms to reduce reusability and open the way to illegal shipments of waste. This exacerbates the pollution haven effect. Conversely, trade with countries that apply similar regulations would preserve the initial intention of these programs: more stringent regulations in the North stimulate green design, reduce illegal shipments, and reduce pollution in the South although the difference in local regulations between the two countries increases. This contradicts the PHH.

International monitoring also plays an important role. Stronger enforcement of international agreements generally leads to reduced illegal shipments of waste and increased levels of reusability. However, when the level of reusability is already high, stronger enforcement makes higher reusability less attractive. In some cases, lowering the level of reusability, compared to improved terms of trade, results in greater benefits. Producers with a high level 
of reusability would therefore respond to stronger international monitoring with adverse behaviours.

To conclude, incentives for changes in green design should not be ignored, because the impact of environmental policies concerning the illegal market and pollution levels is sensitive to firms' responses in terms of reusability level.

\section{Acknowledgements}

Special thanks to Brian Copeland, Louis Hotte, Stan Winer, Hide-Fumi Yokoo, Matthieu Glachant and seminar participants at McGill University, 44th Annual Conference of the Canadian Economic Association, University Paris 1, CERDI, ENGREF Nancy, and the Toulouse School of Economics.

\section{References}

Baggs, Jen (2009) 'International trade in hazardous waste.' Review of International Economics 17(1), 1-16

Beukering, Pieter J.H. Van, and Mathijs N. Bouman (2001) 'Empirical evidence on recycling and trade of paper and lead in developed and developing countries.' World Development $29,1717-1737$

Bond, Eric W. (1983) 'Trade in used equipment with heterogeneous firms.' The Journal of Political Economy 91, 688-705

Clerides, Sofronis (2008) 'Gains from trade in used goods: Evidence from automobiles.' Journal of International Economics 76, 322-336

Copeland, Brian R. (1991) 'International trade in waste products in the presence of illegal disposal.' Journal of Environmental Economics and Management 20, 143-162

Czarnomski, Sarah, and Barry Webb (2006) 'IMPEL-TFS threat assessment project: The illegal shipment of waste among impel member states.' Technical Report, Environment Agency England and Wales, Jill Dando Institute of Crime Science, University College London. 
EEA (2009) 'Waste without borders in the EU? Transboundary shipments of waste.' Technical Report, European Environment Agency

Fischer, Christian, Nanja Hedal, Rikke Carlsen, Karin Doujak, David Legg, Judith Oliva, Sara Lüdeking Sparvath, Matti Viisimaa, Thomas Weissenbach, and Mads Werge (2008) 'Transboundary shipments of waste in the EU. developments 1995-2005 and possible drivers.' Technical Report, European Topic Centre on Resource and Waste Management, European Environment Agency

Fleckinger, Pierre, and Matthieu Glachant (2010) 'The organization of extended producer responsibility in waste policy with product differentiation.' Journal of Environmental Economics and Management 59, 57-66

Frazer, Garth (2008) 'Used-clothing donations and apparel production in Africa.' The Economic Journal 118, 1764-1784

Ino, Hiroaki (2007) 'Extended producer responsibility on oligopoly.' Economic Bulletin $17(6), 1-9$

Janischweski, Jörg, Mikael P. Henzler, and W. Kahlenborn (2003) 'The export of secondhand goods and the transfer of technology.' Technical Report, The German Council for Sustainable Development

Kellenberg, Derek (2010) 'Trading waste.' Technical Report, University of Montana

Kinnaman, Thomas, and Hide-Fumi Yokoo (2011) 'The environmental consequences of global reuse.' American Economic Review 101, 71-76

OECD, ed. (2004) Economic aspects of extended producer responsibility

Rosenthal, Elisabeth (September 27, 2009) 'Smuggling Europe's waste to poorer countries.' The New York Times

Runkel, Marco (2003) 'Product durability and extended producer responsibility in solid waste management.' Environmental and Resource Economics 24, 161-182

Walls, Margaret (2006) 'Extended producer responsibility and product design: Economic theory and selected case studies.' Resource for the Future

Yardley, Jim (April 23, 2010) 'Scrap metal rediation raises concerns in India.' The New York Times

Yoshida, Aya, and Atsushi Terazono (2010) 'Reuse of secondhand tvs exported from japan to the philippines.' Waste management 30, 1063-1072 